\title{
Modeling of Non-Ideal Aluminized Explosives
}

\author{
W.M. Howard \\ L.E. Fried \\ P.C. Souers
}

This paper was prepared for submittal to the 11 th APS Topical Conference on Shock Compression of Condensed Matter

Snowbird, UT

June 27-July 2, 1999

June 1999

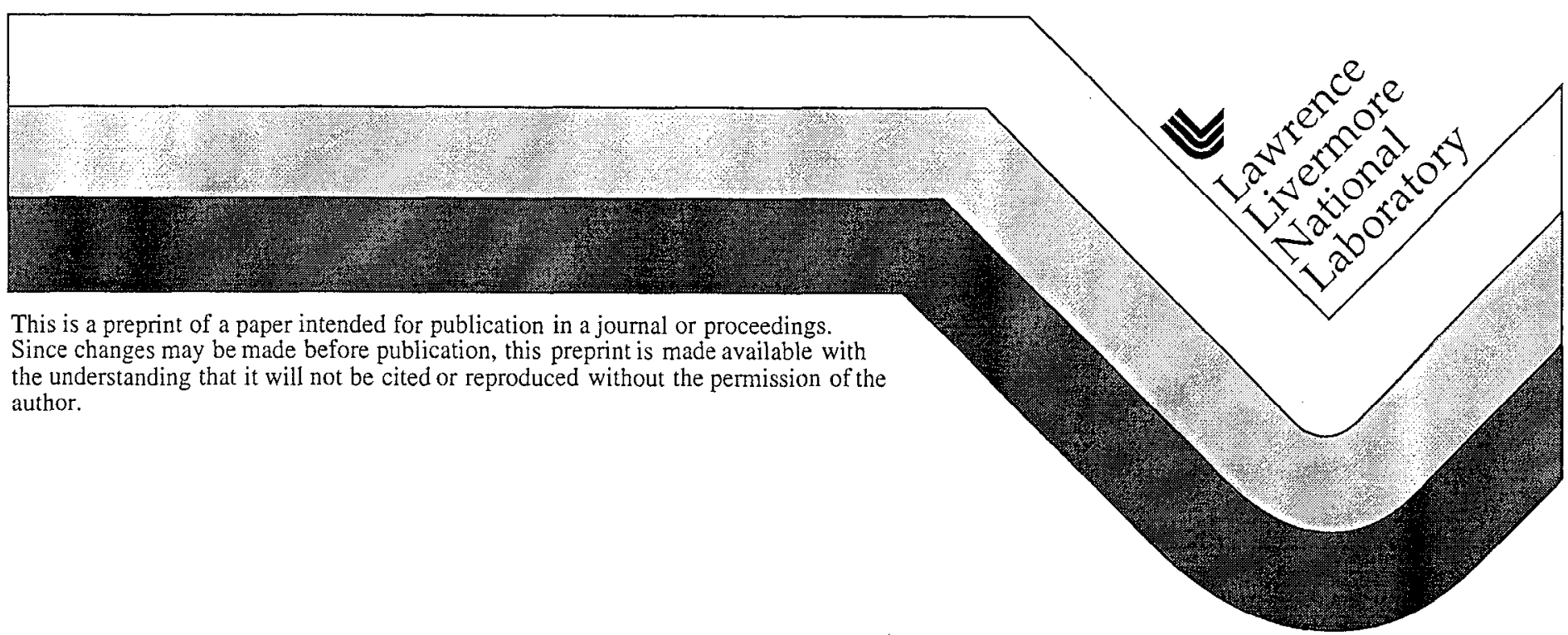




\section{DISCLAIMER}

This document was prepared as an account of work sponsored by an agency of the United States Government. Neither the United States Government nor the University of California nor any of their employees, makes any warranty, express or implied, or assumes any legal liability or responsibility for the accuracy, completeness, or usefulness of any information, apparatus, product, or process

disclosed, or represents that its use would not infringe privately owned rights. Reference herein to any specific commercial product, process, or service by trade name, trademark, manufacturer, or otherwise, does not necessarily constitute or imply its endorsement, recommendation, or favoring by the United States Government or the University of California. The views and opinions of authors expressed herein do not necessarily state or reflect those of the United States Government or the University of California, and shall not be used for advertising or product endorsement purposes. 


\title{
MODELING OF NON-IDEAL ALUMINIZED EXPLOSIVES
}

\author{
W. M. Howard, L. E. Fried and P. C. Souers \\ Energetic Materials Center \\ Lawrence Livermore National Laboratory \\ Livermore, CA 94550
}

\begin{abstract}
We have implemented a Wood-Kirkwood kinetic detonation model based on multispecies equations of state and multiple reaction rate laws. Finite rate laws are used for the slowest chemical reactions, while other reactions are given infinite rates and are kept in constant thermodynamic equilibrium. Within the context of WK theory, we study the chemical interaction between Al and HMX detonation products in non-ideal explosives. We develop a kinetic rate law for the combustion of $\mathrm{Al}$ in a condensed detonation that depends on the pressure and the detonation product gases. We use a Murnaghan form for the equation of state of the solid and liquid $\mathrm{Al}$ and $\mathrm{Al}_{2} \mathrm{O}_{3}$. We find that we can replicate experimental detonation velocities for $\mathrm{HMX} / \mathrm{Al}$ composites to within a few percent for a wide range of aluminum content. We discuss the unccrtaintics in our model and the implications of our results on the modeling of other non-ideal explosives
\end{abstract}

\section{INTRODUCTION}

The detonation of an energetic material is the result of a complicated interplay between chemistry and hydrodynamics. While the detailed chemical kinetics of detonation in gases have been extensively studied, much less is known regarding chemical kinetic processes governing condensed energetic materials. The primary reason for this is the extreme pressure and temperature immediately behind the detonation wave: pressures of $400 \mathrm{kBar}$ $(40 \mathrm{GPa})$ and temperatures of $4000 \mathrm{~K}$ are common. The extreme conditions result in very broad spectroscopic features that make the identification of individual chemical species very difficult.

There is a continuing need in the energetic materials field for reliable predictions of detonation velocity and energy delivery. This has traditionally been accomplished through the means of ChapmanJouget thermodynamic detonation theory. ChapmanJouget detonation theory assumes that thermodynamic equilibrium of the detonation products is reached instantaneously. For the case of "non-ideal " explosives, especially ones containing $\mathrm{Al}$, this may not be the case.

In this study we consider the behavior of "nonideal" aluminized explosives. In particular, we consider HMX/Al composites, for which there is recent experimental data. ${ }^{\prime}$ We define non-ideal explosives as those with a reaction zone of one $\mathrm{mm}$ or more. They are often poorly modeled by Chapman-Jouguet the theory. These materials have chemical reaction rates that are slow compared to hydrodynamic time scale $10^{-6} \mathrm{~s}$ so that the Chapman-Jouguet (CJ) assumption of instantancous thermodynamic equilibrium breaks down. For example, it is found experimentally that the detonation velocity of non-ideal explosives varies sharply from the CJ value and depends strongly on the charge radius. We therefore consider the interaction of chemical kinetics with the detonation wave in order to reach an acceptable representation of detonation in non-ideal explosives. Wood and Kirkwood $^{2}$ (WK) proposed a two dimensional steady state kinetic detonation theory that includes timedependent kinetics and steady -state detonation wave propagation. WK considered a cylindrical charge of infinite length. They solved the hydrodynamic Euler equations in the steady state limit along the central streamline of the cylinder. Radial expansion was treated as a source term in the 1-D flow along the streamline.

In such a case, it is found that the detonation velocity depends on the interplay between chemical kinetics and radial expansion. In the limit of no radial expansion, the ZND plane wave result is obtained. When radial expansion is allowed 
however, the detonation velocity can vary from the C-J prediction. In the limit of strong radial expansion the detonation wave fails; no velocity is found which satisfies the steady-state equations.

In the present paper we implement a model of detonation kinetics based on the identification of individual chemical species. The advantage of the present treatment is that the same equations of state and chemical rate laws can be used on a wide range of explosive mixtures. A mixture equation of state based on thermal, mechanical, and partial chemical equilibrium is used. The mixture model is implemented in the Cheetah thermochemical $\operatorname{code}^{3}$. Small molecules that are gases at standard conditions are treated with the $\mathrm{BKW}^{4}$ real gas equation of state. Solids are treated with a modified form of the Murnaghan ${ }^{5}$ equation of state. Simple pressure-dependent chemical reaction rates are employed. These rates represent the consumption of the energetic material by the detonation wave. Fast reaction rates (partial chemical equilibrium) are assumed for species other than the initial material.

The Wood-Kirkwood equations are solved numerically to find the steady-state detonation velocity. From a previous study, we have determined pressure-dependent kinetic reaction rates for a wide range of explosives and binders, including $H_{M X}{ }^{6}$. The radial expansion was derived from measured radii of curvature for the materials studied. We find good agreement with measured detonation velocities using the same set of equations of state and rate laws for each composite. Although our treatment of detonation is by no means exact, the ability to model a wide range of phenomena based on simple equations of state and rate laws is encouraging. We find that the inclusion of detonation kinetics yields a significant improvement in the predicted detonation velocity of materials with long estimated reaction zones. More importantly, we are able to reproduce the dependence of the detonation velocity on charge radius for several materials. For materials with short reaction zones, we recover the results of Chapman-Jouguet thermochemistry.

\section{WOOD-KIRKWOOD DETONATION THEORY}

WK theory starts with the hydrodynamic Euler equations coupled to chemical kinetics. The theory treats the detonation along the center of the cylinder. The Euler equations are reduced to their steady state form. The result is a set of ordinary differential equations that describe hydrodynamic variables and chemical concentrations along the center of the cylinder.
The notation is as follows: we use cylindrical coordinates in a frame moving with the shock velocity $D . x$ is the axial coordinate, $r$ is the radial coordinate and $u$ is the axial particle velocity in the moving frame (equal to $\mathrm{D}-\mathrm{U}$ in the lab frame). The radial velocity is called $\omega$. Subscripts denote a spatial derivative.

$\mathrm{u}_{\mathrm{x}}=\psi / \eta$
$\rho_{\mathrm{x}}=-(\rho / \mathrm{u})\left(\mathrm{u}_{\mathrm{x}}+2 \omega_{\mathrm{r}}\right)$
$\mathrm{E}_{\mathrm{x}}+\mathrm{p} \mathbf{v}_{\mathrm{x}}=0$
$\mathrm{~F}_{\mathrm{x}}=\mathbf{R} / \mathrm{u}$
$\omega_{\mathrm{r}}=(\mathrm{D}-\mathrm{u}(\mathrm{t}=0)) / \mathrm{R}_{\mathrm{c}}$

where $F$ is the concentration vector, $\mathbf{R}$ is the reaction rate vector and $R_{c}$ is the radius of curvature. $\rho$ is the density, $p$ is the pressure, $E$ is the specific energy and $v$ is the specific volume. We take the form of thesc cquations from Fickett and Davis ${ }^{7}$ (see Equations 5.28 and 5.37). The expression for $\omega_{\mathrm{r}}$ is an approximation that is strictly valid only at the initial jump off of the shock. The reaction rate vector $\mathbf{R}$ is defined, such that

$d \lambda_{i} / d t=\mathbf{R}_{\mathbf{i}} \cdot\left(1-\lambda_{i}\right)$

where $\lambda$ represents the amount of unburned reactant normalized to vary between 0 (all unburned) and 1 (all burned).

We define

$\eta \equiv 1-\mathrm{u}^{2} / \mathrm{c}^{2}$

to be the sonic parameter, where $c$ is the speed of sound. If the sonic parameter $\eta$ is greater than zero communication with the shock front is possible. If it is less than zero the region cannot communicate with the shock front. Secondly, we will define the pressure production term

$\psi \equiv(\partial \mathrm{P} / \partial \mathrm{F})_{\mathrm{V}, \mathrm{E}} \mathbf{R} / \rho \mathrm{c}^{2}-2 \omega_{\mathrm{r}}$

Chemical reactions that increase the pressure at constant $\mathrm{v}, \mathrm{E}$ will increase the value of $\psi$. Radial expansion, however, decreases the pressure through the $\omega_{\mathrm{r}}$ term.

\section{APPLICATION TO ALUMINIZED EXPLOSIVES}

We perform calculations for various mixtures of HMX and Al particles and compare our results with the recent experimental results of Gogulya et al. ${ }^{1}$. In addition to varying the $\Lambda \mathrm{l}$ content, they also varied the Al particle size from $0.5 \mu \mathrm{m}$ to $150 \mu \mathrm{m}$. We 
modeled these experiments with the HMX kinetic rate law from the previous study ${ }^{6}$ and determined an Al combustion rate that best fit the experimental data. We use a rate that depends on pressure, the concentration of $\mathrm{H}_{2} \mathrm{O}$ and a surface term. The rate proportional to $[1-\lambda]^{2 / 3}$ means that the rate is surface area limited, while the rate being proportional to $\mathrm{n}\left(\mathrm{H}_{2} \mathrm{O}\right)$ gives the rate an initiation delay. We find the rate for $\mathrm{Al}$ combustion that gives the best fit to the data is of the form:

$$
\boldsymbol{R}=0.0002 \cdot \boldsymbol{n}\left(\boldsymbol{H}_{2} \boldsymbol{O}\right) \cdot[1-\lambda]^{2 / 3} \cdot \boldsymbol{P}^{2} \mu s^{-1}
$$

where $n\left(\mathrm{H}_{2} \mathrm{O}\right)$ is the concentration of $\mathrm{H}_{2} \mathrm{O}$ in units of moles/ $\mathrm{kg}$ of explosive and $\mathrm{P}$ is in units of $\mathrm{GPa}$. For the rate of HMX decomposition we use

$$
\boldsymbol{R}=0.3 \boldsymbol{P}^{2} \mu s^{-1}
$$

where $\mathrm{P}$ is in units of GPa.
For this study, we have used a BKW equation of state for product gases with parameters fit only to ideal explosives ${ }^{6}$. For $\mathrm{Al}$ and $\mathrm{Al}_{2} \mathrm{O}_{3}$ we have implemented a modified Murnaghan form that fits both shock hugoniot data and the melting curve for both $\mathrm{Al}$ and $\mathrm{Al}_{2} \mathrm{O}_{3}$. We find that the unreated $\mathrm{Al}$ is in the liquid state during the detonation.

The results of our calculations are shown in Figure 1. However, we cannot replicate the Al particle-size dependence of the detonation velocity, A simple surface area scaling of the rate does not replicate the experimental particle-size dependence. For the case of an $\mathrm{Al}$ particle size of $0.5 \mu \mathrm{m}$, excessive $\mathrm{Al}_{2} \mathrm{O}_{3}$ coating of the particles may quench the $\mathrm{Al}$ combustion. Our rate law simulates the general trend of decreasing detonation velocity with increasing the amount of $\mathrm{Al}$ in the composite for larger particle sizes. This rate law predicts that only a relatively small fraction of the $\mathrm{Al}$ reacts in the detonation wave.

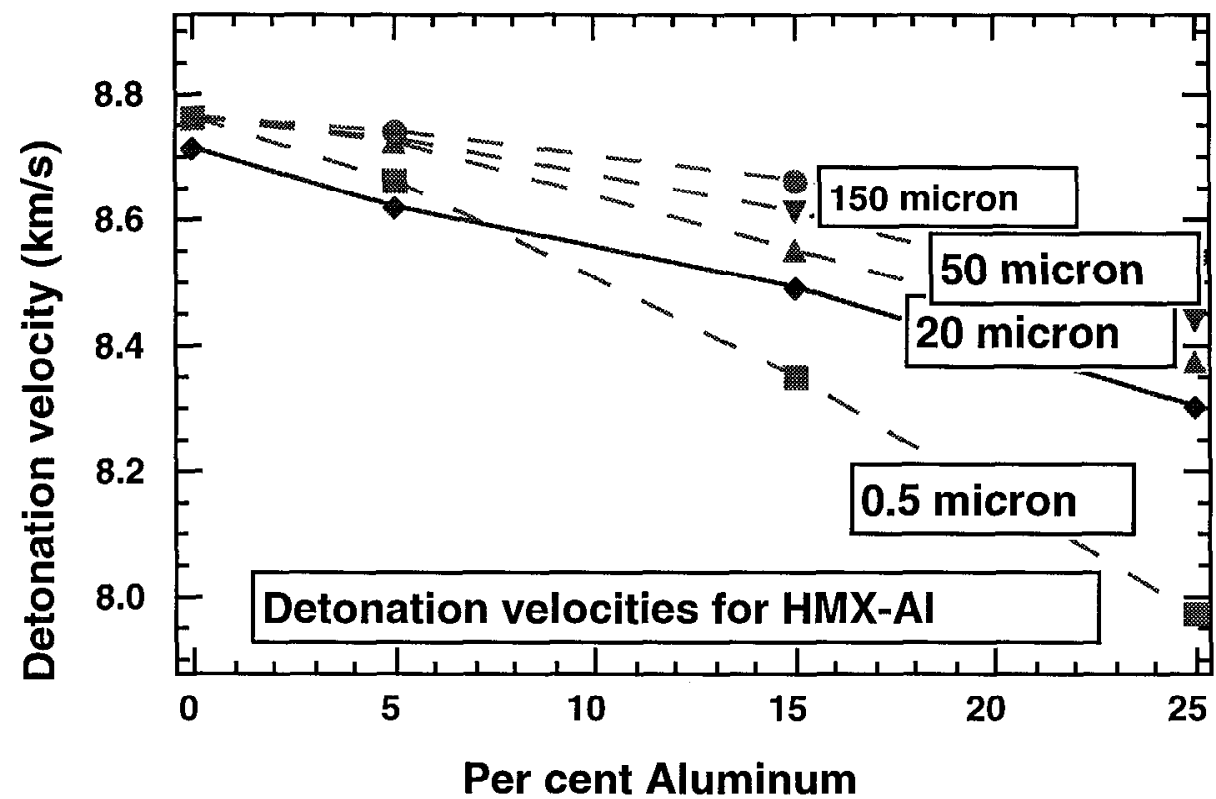

FIGURE 1. Detonation velocities for HMX/AL Composites as a function of Al concentration and particle size. Experimental values (connected by dashed lines) from Ref. 1 are compared to a Kinetic Cheetah calculation (connected by solid line).

Figures 2 and 3 show calculated time histories of the temperature and pressure for various composites. Gogulya et al. measured the temperature and pressure profiles in their experiments with the aid of a dual-channel optical pyrometer. The brightness temperature estimated by measuring the time dependent luminosity intensity at the surface of the composite. The pressure profile was estimated by measuring the temperature response of a liquid boroform layer and using an estimated estimated pressure-temperature response function. Our calculated temperature and pressure profiles are very similar to those estimated by Gogulya et al. for a Al particle size of $50 \mu \mathrm{m}$. That is, the calculated temperatures and pressures are in the range of the experimental values and have the measured dependence on Al content. 


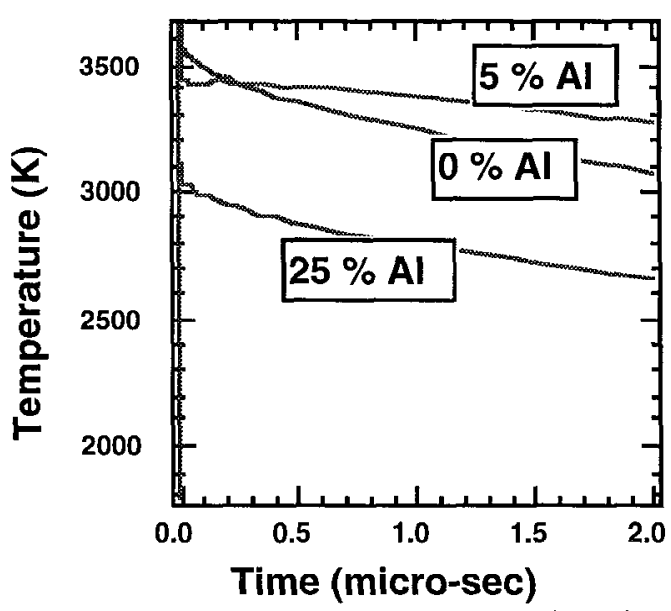

Figure 2. Calculated temperature as a function of time for various $\mathrm{HMX}-\mathrm{Al}$ composites.

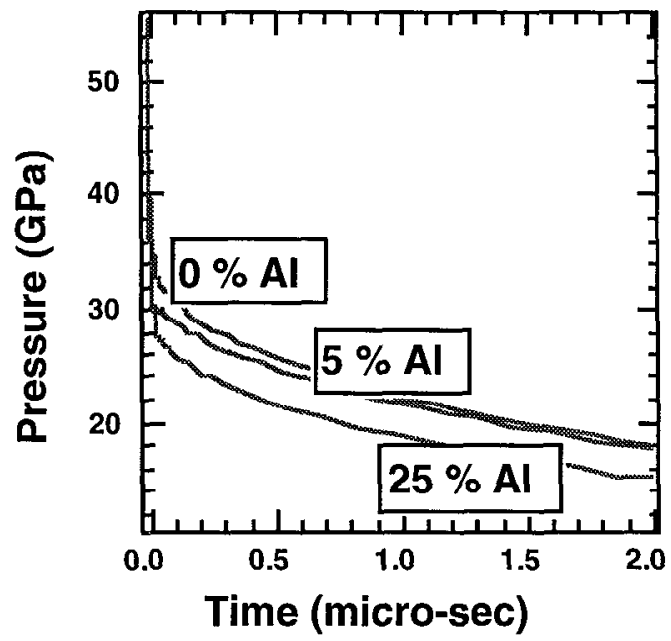

Figure 3. Calculated pressure as a function of time for various HMX-Al composites.

In conclusion we have developed a kinetic model for thermochemical detonations based on WoodKirkwood theory and the thermochemical Cheetah code. We have applied tis model to the case of nonideal explosives with significant $\mathrm{Al}$ content.We find that with a simple model for kinetic processes we are able to model many of the features of non-ideal explosives such as their detonation velocities and the time-dependence of the temperature and pressure. In the future, we plan to extent our kinetic modeling study to include both temperature and pressure dependent rate laws. In this way we can extend our model to more physically based rate laws and study more complex non-ideal detonation behavior such as shock initiation, hot spot formation and failure processes.

\section{ACKNOWLEDGMFNTS}

This work was performed under the auspices of the U. S. Department of Energy by the Lawrence Livermore National Laboratory under contract No.W-7405-48. This work was supported by the Accelerated Strategic Initiative (ASCI) at Lawrence Livermore National Laboratory. We especially thank C. Souers for compilation all of the experimental data, which made this study possible.

\section{REFERENCES}

1. Gogulya, M. F., Dolgoborodov, A. Yu., Brazhnikov, M. A. and Baudin, G. "Detonation Waves in HMX/Al Mixtures (Pressure and Temperature Measurements)", Proceedings of the $11^{\text {th }}$ International Detonation Symposium, Snowmass, Colorado, 30 August to 4 September, 1998.

2. Wood, W. W. and Kirkwood, J. G., "Diameter Effect in Condensed Explosives", J. Chem. Phys., 22, 1954. Pp. 1920-1924.

3. Fried, L. E., Howard, W. M. and Souers, P. C., "CHEETAH 2.0 User's Manual", Lawrence Livermore National Laboratory Report UCRL-MA-117541 Rev. 5, 1998.

4. Fried, L. E. and Souers, P. C., "BKWC: An Empirical BKW Parameterization Based on Cylinder Test Data", Propellants, Explosives, Pyrotcchnics, 21, 1996, pp. 215-223.

5. Murnaghan, F. D., Proc. Nat1. Acad. Sci. (USA), 30, 1944, pp. 244-247.

6. Howard, W. M., Fried, L. E. and Souers, P. C., "Kinetic Modeling of Non-Ideal Explosives with Cheetah", Proceedings of the $11^{\text {llt }}$ International Detonation Symposium, Snowmass, Colorado, 30 August to 4 September, 1998.

7. Fickett, W. and Davis, W. C., "Detonation", University of California Press, Berkeley, 1979, Chapter 5. 